\title{
EVALUATION OF RE-MINERALIZATION OF INITIAL ENAMEL LESIONS USING NANOHYDROXYAPATITE AND CORAL CALCIUM WITH DIFFERENT CONCENTRATIONS
}

\author{
Ali Abdelnabi*, Nermeen Kamal Hamza** and Maha S. Othman***
}

\begin{abstract}
Coral calcium is a boasting natural product and dietary supplement which is considered a source of alkaline calcium carbonate, this study is a comparative study, comparing the remineraliztion effect of the new product of coral calcium with that of nano hydroxyapatite. Methodology: a total of 35 extracted molars were collected, examined and sectioned to obtain 70 sound enamel discs, all discs were numbered and examined by scanning electron microscope coupled with Energy Dispersive Analysis of X-rays(EDAX) for mineral content, subjected to artificial caries and mineral content was re measured, discs were divided into 7 groups according to the remineralizing agent used, where groups 1 to 3 used 10,20,30\% nanohydroxyapatite gel respectively, groups 4 to 6 used 10, 20, $30 \%$ coral calcium gel and group 7 with no reminieralizing agent (control group). All groups were re-examined by EDAX after remineralization, data were calculated and tabulated. Results: all groups showed statistically significant drop in calcium level after artificial caries, all groups showed statistically significant rise in calcium content after re mineralization except for the control group, groups 1 and 5 showed the highest increase in calcium level after re mineralization. Conclusion: coral calcium can be considered a comparative product to nano hydroxyapatite regarding re mineralization of enamel initial carious lesions.
\end{abstract}

KEYWORDS: remineralization, initial caries, enamel, nano hydroxyapatite, coral calcium

\section{INTRODUCTION}

Mineral loss (demineralization) or gain (remineralization) by tooth surface is a dynamic physicochemical process that occurs following the formation of a biofilm on the tooth surface by oral bacteria ${ }^{(1)}$, which is afterwards subjected to fermentable dietary carbohydrates, thus when sugar enters a cariogenic biofilm it is secreted to acids by bacterial metabolism, the biofilm mineral saturation drops, the biofilm attracts minerals from tooth surface in order to compensate this drop, and demineralization occurs ${ }^{(2)}$. A drastically low $\mathrm{pH}$ for tooth minerals dissolution remains for a while, then it

\footnotetext{
* Researcher at the National Research Center, Egypt.

** Lecturer at MSA University.

*** Lecturer of Operative Dentistry, Faculty of Dentistry, Cairo University, Egypt.
} 
returns to physiological limits when sugar exposure phase stops ${ }^{(3)}$. Therefore, when the $\mathrm{pH}$ is elevated and the supersaturating conditions are regained, a certain amount of lost minerals can be reabsorbed by enamel ${ }^{(4)}$. This process is named remineralization, which occur by re-deposition of calcium and phosphate found in bio-film fluid or by direct action of salivary calcium and phosphate. Repetitions of mineral dissolution phase will eventually exceed the ability of oral fluids to compensate mineral loss, and dental caries will start with its first clinical sign which will appear as a white spot lesion ${ }^{(5)}$.

The modern dental practice is focusing on prevention and minimal intervention, and the replacement of lost tooth substances with biomimetic material which is considered as one of the fundamentals of minimal intervention dentistry ${ }^{(6)}$, with the goal of re-mineralizing an incipient lesion rather than extensive surgical replacement. Several methods were introduced to re-mineralize an early tooth structure loss ${ }^{(7)}$.

Fluoride have been known to be effective in the prevention of the incipient enamel lesions in the presence of calcium and phosphate ions, as it advances the development of fluorapatite ${ }^{(8)}$. However, the re-mineralization of initial enamel lesions within the concept of mineral intervention dentistry led to the introduction of several agents and compounds as bio-active formulation of tricalcium phosphate bioactive glass, Recaldent (CPP-ACP) stabilize high concentration of calcium and phosphate ions together with fluoride ions at the tooth surface ${ }^{(9)}$, also another technology in remineralization using the unstabalized amorphous calcium phosphate ACP or Enamelon which applies calcium ions (calcium sulphate) and phosphate ions (ammonium phosphate), sometimes in the presence of fluoride ions, it was claimed that the formation of ACP intra-orally rebuild tooth enamel through re-mineralization (10). Another technology using a bio-active glass containing calcium phosphate
(Novamin) where manufacturer claims that the glass particles release calcium and phosphate ions intra-orally to promote re-mineralization. ${ }^{(11)}$

Therefore, the aim of our study was using recent natural products for re-mineralization of early caries enamel lesions, Coral calcium which are marine invertebrates secreting calcium carbonate to favorably regulate the $\mathrm{pH}$ of the ocean water surrounding them, creating a hard skeleton shelter, with many coral building coral reefs. The mineral skeleton secreted by coral also contains magnesium and many other trace minerals naturally found in the ocean, making coral minerals a broad spectrum mineral supplement. Calcium carbonate are geometrically structured mineral arrangements created by a living organism making them organic minerals with unique properties. The latest advanced imaging science shows that they have organic matrix molecules embedded in the mineral crystals.

Our study was done to compare the remineralizing effect of Coral calcium with nanohydroxyapatite with different concentrations using energy dispersive X-ray (EDAX) to evaluate the degree of deposition of calcium on enamel surface after creating an early caries enamel lesions.

\section{METHODOLOGY}

Specimen preparation: 35 human third molars extracted for orthodontic treatment reasons were collected, examined under stereomicroscope (Olympus SZH10 - Olympus Optical do Brasil, Ltda., São Paulo, SP, Brazil) for cracks and flaws, cleaned and polished by means of a manual dental scaler, polishing paste and rotating brush. Roots were removed by a diamond stone and pulp tissues were eliminated. Teeth were cut by a microtome (ISOMET $^{\mathrm{TM}}$ 1000, Buehler) to obtain 70 sound enamel discs. Discs were coated with acid resistant colored varnish except for a $1 \mathrm{~mm}$ diameter area and stored in distilled water.

Initial mineral content examination: mineral 
content was measured before any treatment by the mean of scanning electron microscope coupled with EDAX

Artificial caries: samples were individually immersed in $10 \mathrm{ml}$ of a demineralizing solution of $\mathrm{pH} 4.3$ without agitation at $37^{\circ} \mathrm{C}$ for 14 days where the solution was changed every other day. The solution contained: $0.1 \mathrm{~mol} / \mathrm{l}$ lactic acid buffer, $0.2 \%$ polyacrylic acid (Carbopol ${ }^{\circledR} 980$ - DEG Importadora de Produtos Químicos Ltda., São Paulo, SP, Brazil), 0.03 ppm F and 50\% saturated with hydroxyapatite (Gen-phos HA - Hospitália Cirúrgica Catarinense Ltda., Florianópolis Santa Catarina, Brazil) at $\mathrm{pH}$ 5.0. To avoid fungal growth in the demineralizing solution, $0.18 \%$ methylparaben was added to it.

Secondary examination: mineral content was re measured after artificial caries

Specimen grouping and reminiralization: specimen were divided equally into 7 groups according to the remineralization gel applied, groups 1 to 7 were remineralized by: 10, 20, $30 \%$ nano hydroxyapatite, $10,20,30 \%$ coral calcium and a control group respectively.
Final examination: mineral content was re measured after re mineralization

Data calculation and evaluation: calcium levels were calculated, mean values were obtained and percentage of change was calculated to detect the re mineralization ability of each gel.Data were explored for normality using Kolmogorov-Smirnov and Shapiro-Wilk tests and showed parametric (normal) distribution.

One-way ANOVA followed by Tukey post hoc test was used to compare between more than two groups in non-related samples.

\section{RESULTS}

\section{Calcium change results:}

A statistically significant difference was found between (Control) and each of (Group 1), (Group 2), (Group 3), (Group 4), (Group 5) and (Group6) where $(p<0.001)$.

Also, a statistically significant difference was found between (Group 5) and each of (Group 2) and (Group 3) where $(\mathrm{p}=0.040)$ and $(\mathrm{p}=0.028)$ respectively.

No statistically significant difference was found between any other pair.

TABLE (1): The mean, standard deviation (SD) values of calcium of different groups.

\begin{tabular}{|l|c|c|c|c|c|c|}
\hline \multirow{2}{*}{ Variables } & \multicolumn{7}{|c|}{ Calcium } \\
\cline { 2 - 7 } & \multicolumn{2}{|c|}{ Before caries } & \multicolumn{2}{c|}{ After caries } & \multicolumn{2}{c|}{ After remineralization } \\
\cline { 2 - 7 } & Mean & SD & Mean & SD & Mean & SD \\
\hline Group 1 (10\% nano) & 46.41 & 2.81 & 24.24 & 2.70 & 45.61 & 3.27 \\
\hline Group 2 (20\% nano) & 46.67 & 3.14 & 26.35 & 4.01 & 43.81 & 3.51 \\
\hline Group 3 (30\% nano) & 45.57 & 0.96 & 26.79 & 3.92 & 43.31 & 1.84 \\
\hline Group 4 (10\% cc) & 45.29 & 2.81 & 27.20 & 3.17 & 44.32 & 3.27 \\
\hline Group 5 (20\% cc) & 44.43 & 3.32 & 24.39 & 2.55 & 47.61 & 2.71 \\
\hline Group 6 (30\% cc) & 45.72 & 2.19 & 26.86 & 4.85 & 43.64 & 4.83 \\
\hline Group 7 (Control) & 47.48 & 1.88 & 26.29 & 1.64 & 28.13 & 5.05 \\
\hline
\end{tabular}


TABLE (2): The mean, standard deviation (SD) values of percentage of change of calcium of different groups.

\begin{tabular}{|l|c|c|c|c|}
\hline \multirow{2}{*}{ Variables } & \multicolumn{3}{|c|}{ Calcium } \\
\cline { 2 - 5 } & \multicolumn{2}{|c|}{ Change } & \multicolumn{2}{c|}{ Percentage of change } \\
\cline { 2 - 5 } & Mean & Mean & SD \\
\hline Group 1 (10\% nano) & 21.37 & 5.50 & 46.39 & 7.25 \\
\hline Group 2 (20\% nano) & 16.26 & 3.13 & 38.24 & 8.64 \\
\hline Group 3 (30\% nano) & 15.72 & 3.21 & 37.09 & 6.00 \\
\hline Group 4 (10\% cc) & 17.12 & 3.04 & 38.62 & 5.95 \\
\hline Group 5 (20\% cc) & 23.22 & 3.70 & 38.64 & 6.19 \\
\hline Group 6 (30\% cc) & 16.78 & 3.05 & 39.06 & 3.67 \\
\hline Group 7 (Control) & 2.04 & 1.01 & 7.26 & \\
\hline p-value & & & $<\mathbf{0 . 0 0 1 *}$ & \\
\hline
\end{tabular}

*; significant $(p<0.05) \quad n s ;$ non-significant $(p>0.05)$

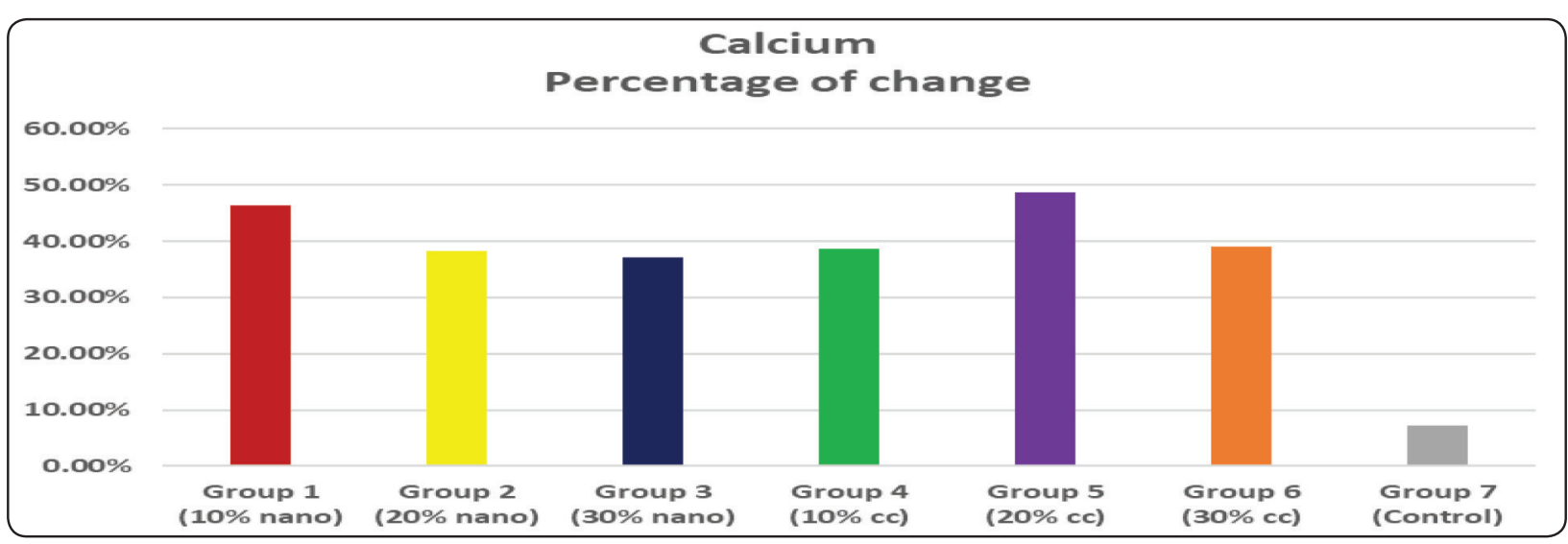

Fig. (1): Representing percentage of change of calcium levels for all groups before and after application of remineralizing gel.

\section{DISCUSSION}

Many products are used nowadays in the remineralization after the understanding of initial caries lesions that can be remineralized with the deposition of calcium and phosphate instead of the surgical intervention ${ }^{(12)}$. Nano sized hydroxyapatite provides a high level of biomimetic properties by its structure, composition and physico-chemical properties, which in turn could represent the key element for remineralization ${ }^{(13)}$, This research was done to investigate the effect of a natural new material, coral calcium on the remineralization of initial caries enamel lesion and comparing it with the nanohydroxyapatite which was documented in many researches its remineralization effect. Coral calcium which is the calcium carbonate, also contains 75 trace minerals which includes yielding calcium, phosphate and magnesium. 
Results showed that there was statistically significant difference between after caries and after remineralization in all groups except control group, in which the highest mean value was found in before caries followed by after remineralization. It was found that all groups had the effect of remineralization with the highest amount of calcium and phosphate precipitation in the enamel surface was the $10 \%$ nanohydroxyapatitethis result came in agreement with kimetal and Huang etal, followed by the $20 \%$ Coral calcium.

Demineralized enamel shows more porosity than sound enamel, which encouraged more penetration of the gel ion components, also showed larger surface area allowing better subsequent reaction of the enamel mineral ${ }^{(14)}$, these factors boosted the potential of nanohydroxyapatite to directly fill up the defects and micro-pores of the demineralized enamel ${ }^{(15)}$, also it allowed the precipitation of calcium from the coral calcium gel on the enamel surface as due to the high concentration of the calcium carbonate present in the coral calcium which leads to deposition of calcium ions by concentration gradient. S B Huang et al demonstrated that $10 \%$ nanohydroxyapatite showed a good effect on remineralization as increasing the concentration will lead to deposition of nanohydroxyapatite on the surface layer which would probably block the surface pores and restrict the diffusion into the lesion over short term of remineralization ${ }^{(16)}$. However, this deposition may eventually reach a stable level even if the concentration increased there will be no statistical difference between the $10 \%$, $20 \%$, or the $30 \%$. Using coral calcium showed a promising effect in the remineralization of enamel surface as our results showed increase in the level of the calcium and phosphate with all concentrations 10, 20 and 30\%, which indicates the deposition of calcium carbonate in the enamel surface.

\section{CONCLUSION}

Coral calcium showed a comparable remineralization ability to nano hydroxyapatite for all groups with the highest at $20 \%$ concentration.

\section{REFERENCES}

1. Jaime AparecidoCury; Livia Maria and AndalóTenuta: Enamel remineralization: controlling the caries disease or treating early caries lesions; Braz. oral res. vol.23 supl.1 São Paulo June 2009

2. Dawes $\mathrm{C}$. What is the critical $\mathrm{pH}$ and why does a tooth dissolve in acid? J Can Dent Assoc. 2003;69:722-4.

3. PaesLeme AF, Dalcico R, Tabchoury CP, Del Bel Cury AA, Rosalen PL, Cury JA. In situ effect of frequent sucrose exposure on enamel demineralization and on plaque composition after APF application and F dentifrice use. J Dent Res. 2004;83:71-5.

4. Alkilzy M, Santamaria RM, Schmoeckel J, Splieth $\mathrm{CH}$ : Treatment of carious lesions using self-assembling peptides. Adv Dent Res 2018a; 29: 42-47.

5. En Cate JM. Current concepts on the theories of the mechanism of action of fluoride. ActaOdontolScand 1999; $57: 325-329$.

6. Lynch RJ, Navada R, Walia R. Low-levels of fluoride in plaque and saliva and their effects on the demineralisation and remineralisation of enamel; role of fluoride toothpastes. Int Dent J 2004;54(5 Suppl):304-309.

7. Dye BA, Vargas CM, Fryar CD, Ramos-Gomez F, Isman R: Oral health status of children in Los Angeles County and in the United States, 1999-2004. Community Dent Oral Epidemiol 2017; 45: 135-144.

8. Gonzalez-Cabezas C, Fernandez CE: Recent advances in remineralization therapies for caries lesions. Adv Dent Res 2018; 29: 55-59.

9. EC Reynolds: Calcium phosphate-based remineralization systems: Scientific evidence. Australian Dental journal. 2008; volume 53, Issue 3

10. Kaehler T: Nanotechnology-basic concepts and definitions. Clin. Chem. 40 1797-99

11. Juntavee N, Juntavee A, Plongniras P: Remineralization potential of nano-hydroxyapatite on enamel and cementum surrounding margin of computer-aided design and 
computer-aided manufacturing ceramic restoration. Int J Nanomed 2018; 13: 2755-2765

12. Huang S B, Gao SS, Yu H Y:Effect of nano-hydroxyapatite concentration on remineralization of initial enamel lesion in vitro. Biomed. Mater. 4 (2009) 034104

13. Kim M Y, Kwon H K, Choi C H and Kim B:Combined effects of nano-hydroxyapatite and $\mathrm{NaF}$ on remineralization of early caries lesion. Key Eng Mater. (2007): 330-332, 1347-50

14. Yamazaki H, Litman A and Margolis H C: Effect of fluoride on artificial caries lesion progression and repair in human enamel: regulation of mineral deposition and dissolution under invivo like conditions. Oral Biol.. 2007; 52, 110-120

15. Yang Y, Lv X, Shi W, Zhou X, Li J, Zhang L: Synergistic inhibition of enamel demineralization by peptide 8DSS and fluoride. Caries Res 2016; 50: 32-39.

16. Kind L, Stevanovic S, Wuttig S, Wimberger S, Hofer $\mathrm{J}$, Muller B, Pieles U: Biomimetic remineralization of carious lesions by self-assembling peptide. J Dent Res 2017; 96: 790-797. 